\title{
Pediatric radiology editorial board - acknowledgments and updates
}

\author{
Peter J. Strouse
}

Published online: 3 December 2014

(C) Springer-Verlag Berlin Heidelberg 2014

The Editorial Board for Pediatric Radiology is listed in the front of each issue of the journal. Individuals are invited to serve on the journal's Editorial Board because of their expertise and experience in subject matter, their established record of excellence, availability and reliability in reviewing, and in recognition of other contributions to the journal.

Editorial Board membership is not honorary. The Editorial Board of Pediatric Radiology is a working editorial board. Editorial Board members do a greater number of reviews and provide reviews on papers that are challenging, controversial or obscure in nature. In addition to reviews, members of the Editorial Board contribute as subject matter experts. Editorial Board members assist the editors as consultants and by identifying new reviewers to add to our team. Editorial Board members are occasionally asked to contribute commentaries on important and controversial articles. Editorial Board members are asked to contribute to the journal in the form of review articles, minisymposia and other special projects at least once every 3-5 years. These contributions undergo the standard review process.

A new category of "Quality and Safety" has been added within the Editorial Board. This addition is warranted to address the increasing attention to these issues in our workplaces and in our journal content.
The composition of the Editorial Board of Pediatric Radiology is re-evaluated and updated yearly. The new board takes effect with the January issue of each volume (year). Service is not term-limited.

The editorial team is extremely grateful to our Editorial Board members for their important contributions to the journal. Success of the journal is dependent on the expertise, guidance and contributions of the community of experts in pediatric imaging and related subjects. We would like to sincerely thank the following outgoing Editorial Board members for their years of excellent service to the journal:

Alan Daneman, Toronto (General Pediatric Radiology)

James Meyer, Philadelphia (Oncology)

We would like to welcome the following incoming Editorial Board members:

David Larson, Palo Alto (Quality and Safety)

Ethan Smith, Ann Arbor (Oncology)

Marwan Zidan, Detroit (Statistics)

Conflicts of interest None

P. J. Strouse $(\square)$

Section of Pediatric Radiology, Department of Radiology,

C. S. Mott Children's Hospital,

University of Michigan Health System,

Room 3-231 1540 E. Hospital Drive,

Ann Arbor, MI 48109-4252, USA

e-mail: Rad-Ped-Radiol-Journal@med.umich.edu 